\title{
Erratum to: Antioxidant Rescue of Selenomethionine-Induced Teratogenesis in Zebrafish Embryos
}

\author{
M. C. Arnold ${ }^{1}$ J. E. Forte ${ }^{1}$ J. S. Osterberg ${ }^{1}$ - R. T. Di Giulio ${ }^{1}$
}

Published online: 4 August 2016

(c) Springer Science+Business Media New York 2016

Erratum to: Arch Environ Contam Toxicol (2016)

70:311-320

DOI 10.1007/s00244-015-0235-7

The original publication incorrectly states that manganese superoxide dismutase-2 ( $\operatorname{sod} 2)$ was measured during the experiment. Copper/zinc superoxide dismutase-1 $(\operatorname{sod} 1)$ was actually measured using the following primers for sodl (GeneBank ID Y12236): forward primer 5'-CTA GCC CGC TGA CAT TAC ATC-3', reverse primer 5'-TTG CCC ACA TAG AAA TGC AC- $3^{\prime}$. The primer sequences listed in Table 1 for sod 2 are incorrect.

The online version of the original article can be found under doi:10.1007/s00244-015-0235-7.

\footnotetext{
M. C. Arnold

Mariahc.arnold@gmail.com

1 Nicholas School of the Environment, Duke University,

Box 90328, Durham, NC 27708, USA
} 